\title{
COLIGAÇÕES PARTIDÁRIAS: Verticalizar ou Não-Verticalizar
}

\author{
Monica Herman Caggiano
}

\begin{abstract}
Resumo:
A figura da verticalização que, ım 2002, por força das instruções editadas, do Tribunal Superior Eleitoral e com o ensejo de regulamentar o art. $6^{\circ}$ da Lei n. 9.504 , de 30 de setumbro de 1997, visando aos pleitos nacional e estaduais foi reintroduzida no processo eleitoral.

Palavras-chave: Processo eleitoral. Eleições. Verticalização. Candidaturas. Do princípio da anualidade e o processo eleitoral. O princípio da legalidade. Regulamento. Regulamento praeter-legem. Eleições 2006. Cidadão-cleitor. A Resolução n. 20.993, de 26 de fevereiro de 2002 do TSE:
\end{abstract}

\begin{abstract}
:
This paper is about verticalization in political elections in Brazil, introduced in Brazil in 2002 by instructions enacted by the Brazilian Supreme Ellection Court, in order to rule article 6 of the Law n. 9.504, September $30^{\text {th }} 1997$, applicable to national and state elections, that was reintroduced in next elections.

Keywords: Elective procedures. Elections. Verticalization. Nominations. One-year principle and clection procedures. Legality Principlc. Rules. Praeter Legem Rules. Ellections in 2005. Elcctor-Citizen. Resolution TSE $n$. 20.993, February $20^{\text {th }}, 2002$.
\end{abstract}

Ano eleitoral provoca efervescências desde os seus primeiros dias. () cenário político ingressa num ritmo mais acelerado e na medida em que a data do pleito vem se avizinhando os ânimos, as idéias e a busca de inovações - ora aproveitando a um. ora a outro dos segmentos da arena em que se dá a competição eleitoral - emergem com um potencial cada vez mais proeminente. Enfim, descortina-se um florescente espaço a propostas mirabolantes, todas, supostamente, de prontidão para o aprimoramento da consulta eletiva e de seus resultados.

1. A Resolução n. 20.993, de 26 de fevereiro de 2002 do TSE

I:m 2002, por força das Instruções editadas pelo Tribunal Superior Eleitoral (Resolução n. 20.993. de 26 de fevereiro de 2002), 'e com o escopo de regulamentar o

Professora Associada do Departamen:o de Direito do Estado da Faculdade do Direito da Universidade de São Paulo. Professora Citular de Direito Constitucional da Faculdade de Direito da Universidade Presbiteriana Mackenzie. 
disposto na I.ei n. 9.504, de 30 de setembro de 1997 (ar\% 6\%), com vistas ao pleito nacional e aos estaduais, foi reintruduzida ${ }^{2}$ a figura da verticalização. A fórmula proibia a efetivação de coligações ${ }^{?}$ autônumas e independentes no âmbito dos plcitos eletivos previstos: a) a sleição para a Prısidência da República, que ocorre em esfera nacional, e para aqueles que têm os Estados-membros como circunscrição, todos, é verdade, a se realizar numa única data. Em suma, estabeleceu uma grave restrição ao cidadão, à sociedade, à autonomia dos partidos políticos, ao corpo eleitoral e aos candidatos, ferindo a liberdade de apresentação di candidaturas. $E$ isto por via de mero regulamento, porquanto Instrução baixada pela Justiça Eleitoral, na hierarquia legal. ocupa exatamente este nivel.

Preconizava aludida norma:

Os partidos políticos que lançarem. isoladamente ou em coligação, candidato à eleição de presidente da República não poderão formar coligações para eleição de governador/a de Estado ou do Distrito Federal, senador/a, deputado/a federal e depulado/a estadual ou distrital com partido politico que tenha, isoladamente ou em aliança diversa. lançado candidato/a à eleição presidencial - grifo nosso.

Utilizou-se aludida Resolução do TSE da técnica da vinculação vertical para as candidaturas em coligação. Forçoso ressaltar, porém. que a imposição da fórmula, que passou a ser conhecida como a da verticalização, investiu fortemente contra a autonomia partidária, resguardada pela nossa ('onstituição de 1988 (arr. 17), documcnto que convím anotar - somente admite a intervenção do legislador ordinário para disciplinar o funcionamento parlamentar das agremiações, a propaganda eleitoral e a questão financeira. Nada mais.

Mais, ainda, investiu contra o princípio constitucional que exige lei (legalidade estrita) para o disciplinamento do processo eleitoral. Fste escaninho é

\footnotetext{
Instrução n. 55 - Classe $12^{3}$ - Distrito federal (Brasilia)/ Relator Ministro Fernando Neves.

Utilizamos a expressão reintrodução, porque a idéia da verticalização já foi praticada entre nós. De fato, oportuno lembrar que a vinculação fora utilizada na década 80 , com o escopo de robustecer o desempenho eleitoral do partido sutuacionista, já em franco processo de desgaste. Á época, a vinculação prevista pela Lei n. 6.978, de 19.01.1982 (art. $8^{\circ}$ ), com a redação dada pela Lci n. 7.015, de 16. 07. 1982, dispunha: "o eleitor votará apenas em candidatos pertencentes ao mesmo Partido, sob pena de nulidade do voto para todos os cargos" A rórmula atingia os pleitos estaduais para a cleiçăo do govemador, do senador. dos deputados federais e dos deputados estaduais. E, diante dessa limitação a intimidar a exteriorização da vontade politica. decorrente da obrigatoriedade de votar em candidatos de um só partido, surgiu o célebre voto camarão, figura desenvolvida a partir da possibilidade de abstençào do eleitor. Poderia este votar em qualquer candidato. desde que não declarasse o seu voto quanto ao cargo majoritário, cabeça da chapa, que cra o de Governador. Assim, pois, conclamava o partido governista, no ensejo de salvar seus candidatos e diante da manifesta repulsa pelo candiclato oficial ao Governo do listado, a que o eleitor votasse nos candidatos da chapa, cortando, no entanto, a cabeça desta. isto é: recomendava-se a abstenção quanto à uleiçào para govemador. Sobre candidatura e o processo de coligação, ver ainda o nosso Direito Parlamentar a Direito Eleitoral. Barueri, São Paulo, Manole, 2004.
} 
comandado pela standard da reserva legal sendo vedada ação do regulamento que se afigura inferior. Aliás, sob este aspecto oportuno advertir, recorrendo ao magistério de Ferreira Filho que anota:

....o regulamento não pode criar ou extinguir obrigaçðes, não pode nem mesmo suspendê-las ou adia-las, como não amplia nem restringe direitos. Por outro lado, se costuma ensinar que, no que for além da lei, não obriga; no que for conta a lei, não prevalece. $\underline{\dot{A}}$ luz desse ensinamento, que é o clássico. o regulamento "pareter legem" não obriga. (Manoel Gonçalves Ferreira Filho, Curso de Direito Constitucional, São Paulo, Saraiva, 2001- $f 7 s$ 279) ${ }^{4}$

E mais até, ainda que se admitisse, hipoteticamente, a viabilidade da inserção da vinculação verticalizada a título de reorientação do processo eleitoral, esta deveria atender, como seria de se esperar, a limitação no tempo, de l (hum) ano, ${ }^{5}$ imposta constitucionalmente para a reforma das normas incidentes sobre a realização de pleitos eletivos.

Investiu, ademais, contra o cidadão-eleitor, não lhe autorizando o leque de opções a que teria acesso na hipótese da inocorrência desse tipo de restrição. Isto porque impondo aos partidos a obrigação de realizar, em panorama estadual, idêntica coligação à consagrada em esfera nacional, a técnica acolhida implica flagrante redução das possibilidades de acordos a nível regional e local e, daí. da diversidade de arranjos que poderiam, eventualmente, ser apresentados ao eleitor.

Desde logo contestada, referida Resolução n. 20.993/2002 que, em fevereiro do ano eleitoral de 2002, mudava as regras para fins de apresentação de candidaturas aos pleitos que viriam a se realizar em outubro deste mesmo ano, distanciando-se da regulamentação anteriormente oferecida ao art. $6^{\circ}$ da Lei n. 9.504/97, passou pelo crivo do STF. por força das ADins 2628-3 e 2626-7. O Excelso Pretório não enfrentou a questão diretamente. Deixou assente, no entanto, tratar-se de questão de legalidade conformação do regulamento à lei - e, daí, a matéria poderia vir a ser questionada no âmbito da Justiça Eleitoral por ocasião do registro das candidaturas. ${ }^{6}$ Isto porque, o que se discutia era a adequação do regulamento (Resolução $n$. 20.993/2002) à lei (art. $6^{\circ}$ - Lei $n$. 9.504/97).

\footnotetext{
Ver, ainda, do mesmo autor, Do Processo Legislativo, S. Paulo. Saraiva, 2001.

$\dot{E}$ o art. 16 da Constituição Federal, inserido pela E.C. n. 4/93. que dispõe: "A lei que alterar o processo eleitoral entrarci em vigor na data de sua publicação, não se aplicando à eleição que ocorra até um ano da data cle sua vigência"
}

ADins 2628-3 e 2626-7 /Ementa em ambos os casos: "Ação Direta de Inconstilucionalidade. Parágrafo $1^{\circ}$ do art. $4^{\circ}$ da Instrução n. 55, aprovada pela Resolução n. 20.993, de 26.02.2002, do Tribunal Superior Eleitoral. Art. $6^{\circ}$ da Lei n. 9.504/97. Eleições de 2002. ('oligaçäo Partidária. Alegação de ofinsa aos arts. $5^{\circ}$. II e LIV. $16,17, \S 1^{\circ}, 22, I$ e 48 , caput da Constituição Federal. Ato Normativo Secundário. Violação Indireta. Impossibilidade de controle abstrato de constitucionalidade" E mais, restou assentado: "... Nienhum dispositivo da ( onstituição Federal se ocupa diretamente de coligações partidárias ou estabelece o âmhito das circunscrições em que se disputar: os pleitos eleitorais, exatamente, os dois pontos que levaram à interpretação pelo TSE. Sendo assim, nào há como vislumbrar of unsa direta a qualquèr dos dispositivos constitucionais". 
É verdade que o próprio TSF retrocedeu, acabando por suavizar a intensidade da restrição idealizada. Em abril de 2002, o Diário da Justiça, edição do dia 19, estampava as Resoluções de n. 21.045 e n. 21.046 , ambas de 26 de março de 2002, resultantes das Consultas, respectivamente de n. 758/DF e 759/DF, onde buscava apaziguar o clima de intranqüilidade instalado, assegurando: "Partidos políticos que não estcjam disputando a eleição presidencial podem se unir a outros na mesma situação para disputar outras eleições" (item 6/ Res. 21.045) e proclamando: "Partidos políticos que não estejam disputando, isoladamente ou em coligação, a eleição presidencial podem celebrar coligações para disputar eleições estaduais iom partidos politicos que estejam, isoladamente ou em coligação, disputando u eleição presidencial' (item 2/ Res. 21.046).

De qualquer forma, fragilizada por força dos múltiplos ataques e, principalmente, pela atenuação com que o próprio autor, o F. Tribunal Superior Eleitoral, contemplou esta figura, a verticalização passou, de forma célere, para a coluna das meras ficções, deixando de produzir os efeitos desejados pelos idealizadores.

De rigor, o yuadro das coligações de 2002 oferece uma visão de acordos heterodoxos, carentes de coerência política e absolutamente distantes da perspectiva de fixar o caráter nacional dos partidos brasileiros para fortalecê-los, como pretendia o seu defensor, ministro Nelson Jobim do E. Tribunal Superior Eleitoral. Daí a presença de acordos inéditos e altamente surpreendentes, a exemplo da coligação do PL com o PT a nível nacional e com o PPB no Estado de São Paulo, e o PMDB concluindo, no Estado do Maranhão, coligação com o PSDB e o PFL em âmbito estadual e, mediante entendimentos de apoio, com o PT para a eleição presidencial.

\section{A PEC n $548 / 2002$}

Estamos em 2006. Janeiro. Por mais uma vez em fase preparatória de consulta eleitoral, no periodo de carência, de um ano, estabelecido pelo art. $16 \mathrm{da}$ Constituição Federal. O pleito, por mais uma vez, envolve eleições gerais, a abarcar a escolha do presidente e vice-presidente da República, governadores e vice-governadores dos Estados-membros, deputados federais, deputados estaduais e 1/3 dos senadores. E, exatamente, neste momento uma Emenda Constitucional (PEC 548/2002 do Senado) reinicia sua marcha processual, retomando seus trâmites no Congresso Nacional. Referida PEC, que acaba de ser aprovada pela Câmara dos Deputados, ao prever nova redação para o $\S 1^{\circ}$ do art. 17, do nosso Estatulo Fundamental, aproveita para afastar definitivamente a possibilidade de vir a se instalar a fórmula da vinculação nos processos eletivos.

Veja-se a redação da norma no estágio atual e com a nova construção, na forma proposta pela referida PEC: 
('onstituição Federal -art. 17,\$ $1^{\circ}$

\$ I" É assegurada uos partidos politicos antonomia para definir sua estrutura interna. orgunização ' funcionaminto, divendo sens estanutos estabelecer normas di fidelidade $\varepsilon$ disciplina partidarias.
Constituição Federal - art. $17, \S 1^{\circ}$, com a alturação proposta pela PEC 548/02

$\S I^{\circ} \dot{E}$ assegurada aos partidos politicos autonomia para definir sua estrutura interna, organizaçào e funcionamento $\underline{e}$ para adotar os critérios de escolha e o regime de suas coligações eleitorais, sem obrigatoriedade de vinculação entre as candidaturas em nivel nacional, estadual, distrital ou municipal, devendo seus estatutos estabelecer normas de fidelidade e disciplina partidarius.

()ra é estarrecedor o próprio constituinte vir a propor a alteração da regra eleitoral, sob o risco, inclusive, de lesar o principio da anualidade estabelecido no bojo da Lei Maior (art. 16). preceitu que visa assegurar a anterioridade da norma de regència do processo eleitoral, impedindo os casuísmos, as normas de última hora e os privilegiamentos.

A mudança sugerida, contudo, não reformula a regra contida no citado dispositivo. $\mathrm{Na}$ realidade, na sua redação atual, referido preccito do art. $17, \S 1^{\circ}$, não impõe, de per si, a verticalização. Esta foi produto, em 2002. de mero artificio; ingressou na órbita eleitoral por via de regulamento expedido pelo TSE (Resolução n. 20.993, de 26 de fevereiro de 2002), um regulamento criticado, carecedor do atributo de legalidade condição elementar do Estado du Dircito, como moldada a federação brasileira - e manifestamente lesivo à liberdade que deve envolver as consultas eleitorais em ambientes democráticos. ${ }^{7}$ Enfím, a proposta de Emenda visa, tão só, elucidar e garantir a umplitude de ação partidària, referunte à possihilidad' de variadas gamas de coligações, o que. aliás, já estava vislumbrada, embora, certo é que não de forma lão explíciti.

Conquanto quéstionada e discutida remodelação do $\$ 1^{\circ}$, do art. 17 , da Constituição, não altere substancialmente o conteúdo do preceito, ${ }^{8}$ a verdade é que vem provocando intensa movimentação parlamentar e partidária, encontrando-se já claramente constituida uma linha divisória entre os que estão a favor e os que se posicionam contra a receita da verticalização. De ambos os lados mera especulação política. Um jogo de interesses, pressionando alguns (os partidos de maior robustez) para fazer valer a regra da verticalização (ilegal e inconstifucional desde a sua origem em 2002), セ outros (partidos de médio e pequeno porte) buscando o fortalecimento da norma constitucional, hoje em vigor, que não prevê limites a uma ampla e diversificada rede de coligações que venham a sur concretizadas pulos partidos em nivel nacional e no regional; ao invés preccitua a autonomia partidária, até mesmo no tocante à formalização de alianças.

De qualquer forma, a mera propositura de nova regra incidente sobre os processos eleitorais de 2006. em janeiro de 2006, importa situação marginal e descompromissada com o principio da segurança jurídica, que exsurge na trajetória evolutiva da idéia de Estado de Dircito. buscando assegurar-lhc reforço. Este standard, produzido em esfera germânica, onde se encontra constitucionalmente protegido,

\footnotetext{
Ver neste sentido, o nosso Direito Parlamintar e Direito Eleitoral. Barueri - SP: Manole, 2004.

8 Configura apenas uma intervenção explicativa, de fins didáticos - talvez - e com toda certeza de finalidade assecuratória quanto à liberdade e autonomia partidária en relação ao tópico: possibilidades de coligação.
} 
rapidamente conquistou a simpatia da doutrina e da jurisprudência no panorama europeu. Em França, se instalou como reflexo do direito comunitário em expansão e, embora ainda não tenha sido contemplado de forma expressa em nível constitucional. vai se robustecendo ganhando espaço próprio em textos legais, no âmbito da doutrina e da jurisprudência.

Um de seus primordiais atributos reside em se consubstanciar em indicador de qualidade do direito, conduzindo Bertrand Mathieu a explicitar: "A segurança juridica exprime, pois, um certo número de exigências as quais deve atender o direito enquanto instrumento. Ela condiciona a realização da "proeminência do direito"?

textraído. pois, do direito comunitário europeu, ${ }^{10}$ o princípio da segurança jurídica repousa sobre a idéia do prévio conhecimento da lei e do tratamento ao qual essa será submetida na sua aplicação. Apresenta-se como macroprincípio, alojando no seu bojo outros princípios, a exemplo da confrança legítima, da legalidade ou da qualidade da lei.

Nessa visualização, portanto, o analista viria a se deparar, de um lado, com os princípios direcionados à exigência de qualidade do direito e, de outro, com os atinentes à imposição de previsibilidade do direito.

Daí porque, sob a perspectiva da segurança jurídica, pecava a atacada Resolução (Resolução n. 20.993, de 26 de fevereiro de 2002), por ignorar o princípio. introduzindo uma regra restritiva à liberdade ampla de expressar posturas políticas, quer no pólo ativo - pelo voto, quer no passivo, em admitir as mais diversificadas opções colocadas à disposição do eleitor. E, hoje, peca o constituinte por pretender uma reformulação de norma constitucional num período vedado a remodelações eleitorais. Tal processo, conquanto não altere a substância da norma, investe contra a previsibilidade do direito, eixo ao redor do qual gira o princípio da anualidade do art. 16 da Constituição. ミ, certamente, em homenagem a estes princípios da anualidade e da previsibilidade é que seria recomendável não avançar com a tramitação da PEC n. 548/02 do Senado. Consagraria esta a postura mais consentânea e alinhada ao respeito que o próprio legislador constituinte reformador deve à máxima da segurança jurídica.

Afirmava Rousseau, no seu Contrato Social, que o voto consubstanciava "Ln droit que rien ne peut ôter aux citoyens" Mas para que o exercício desse direito venha a efetivamente qualificar o cidadão-eleitor é mister que atenda à imposição de liberdade de escolha ou seleção e à liberdade de apresentação de candidaturas. E mais, tudo isto num clima de segurança jurídica que deve coroar o processo eleitoral para o fim de garantir resultados que, de fato, atendam às expectativas da comunidade social.

9 "Constitution et Securité Juridique", relatório apresentado na Xve Table Ronde Internationale, Aix en Provence, setembro de 1999, pelo Prof. Bertrand Mathieu . da Universidade de Paris 1, Panthéon Sorbonne. com o auxilio de Anne Laure Velembois, monitora da Faculdade de Direito e de Ciências Politicas de Dijon.

10 Esse standard, qui implica na proteção da confiança juridica foi inserido de forma implicita na ordem juridica da Comunidade européia pela decisão da Comissão C. Conseil de 5.06.1973, confirmada de modo expresso pela decisão Töpfer, de 3.05.1978, onde restou assente que a ignorância dessa máxima constitui violação de tratado ou de qualquer regra de direito no tocante a sua aplicação. In Recueil de Jurisprudence Constitutionnelle. p. 575 e 1019 


\section{Conclusões}

I.- A Resolução n. 20.993/2002 que, em fevereiro do ano eleitoral de 2002, introduziu o fenômeno da verticalização, já, àquela época, encontrava-se inquinada pclo vício da ilegalidade, apresentando-se claramente portadora de deficiência própria do "regulamento praeter legem" que, à luz do Direito Constitucional clássico, não pode e, de fato, não obriga.

2.- A tramitação e a eventual promulgação da Emenda Constitucional em processo de elaboração legislativa, por intermédio da PEC 548/2002, não desautorizará a aplicação correta da norma contida no $\S 1^{\circ}$. do art. 17 , da Constituição Federal. às eleições gerais de 2006. A remodelação preconizada consubstancia-se mais num reforço, explicativo da abrangência do aludido preceito, não the alterando a substância. A norma - com ou sem a nova redação - terá incidência regular sobre os pleitos, consagrando a autonomia da agremiação político-partidária. inclusive no que concerne sua competência decisória acerca da oportunidade e conveniência das coligações para lançamento de candidaturas.

3.- A viabilidade de edição e aplicação do dispositivo visado pela referida PEC 548/2002, parece evidente. Não modifica em sua substância a norma que visa reformar (art. 17, $\S 1^{\circ}$, (.$F$.) e, portanto, não altura o processo eleitoral. Constitui uma remodelação elucidativa da mens legislatoris. É só. Ademais, introduzida por via de Emenda Constitucional, não incide na vedação do art. 16 da Lei Maior. Essa dirige-se ao legislador ordinário, impondo-Ihe um prazo de carência (um uno) para a edição das normas de regência dos processos eleitorais.

Contudo, por mais uma vez. estará se colocando na penumbra o standard da segurança jurídica. Este exige a previsibilidade do direito, o que in casu somente se alcançará mediante o pleno atendimento da regra da anualidade estabelecida, para o panorama eleitoral, no art. 16 da Constituição Federal.

São Paulo, dezembro de 2005. 